\title{
Geologia
}

\section{Lodo de Esgoto da ETE Barueri - SP: Proveniência do Enxofre Elementar e Correlações com Metais Pesados Associados}

\section{ETE Barueri - SP Sewage Sludge Elementary Sulfur and Heavy M etals Correlation}

\author{
Joel Barbujiani Sígolo (jbsigolo@usp.br) e Cyntia Helena Ravena Pinheiro (chhrpin@usp.br) \\ Departamento de G eologia Sedimentar e Ambiental - Instituto de Geociências - USP \\ R. do Lago 562, CEP 05508-080, São Paulo, SP, BR
}

Recebido em 30 de maio de 2007; aceito em 17 de novembro de 2009

RESUMO

A ocorrência frequente de enxofre no lodo de esgoto coletado na Estação de Tratamento de Esgoto de Barueri (ETE) relaciona-se principalmente à presença de surfactantes, provenientes de detergentes descartados em grande quantidade nos esgotos domésticos. Os resultados da análise de isótopos de enxofre obtidos em amostras de lodo indicam possível correlação com a queima de combustíveis fósseis, bem como a presença de fertilizantes encontrados nos solos carreados pelo fluxo das águas pluviais e fluviais. O ambiente redutor do tratamento anaeróbio na ETE pode propiciar a formação de enxofre elementar identificado nesse trabalho. A sua presença pode ser verificada em espectros obtidos por difração de raios X e análises pontuais realizadas nos cristais observados nas amostras de lodo de esgoto com o auxílio do Energie Dispersive Scan (EDS) acoplado a Microscópio Eletrônico de Varredura (MEV).

Palavras-chave: Metais pesados; Enxofre elementar; Lodo de esgoto; Isótopos de enxofre; Contaminação.

\begin{abstract}
The presence of sulfur in sewage sludge from the Barueri Sewage Treatment Plant (STP) seems to be related to the presence of surfactants and feces, both present in domestic wastewater. The results obtained demonstrate a possible correlation with combustion of fossil fuels, that show by isotopic sulfur analyses and results in sewage sludge samples. Fertilizers are also present in the soils due to transport by fluvial and pluvial waters. The reducing environment at anaerobic treatment may have favored the formation of elemental sulfur identified in this study. Its presence was indicated using $\mathrm{X}$-ray diffraction patterns, and point analyses of crystals present in the sewage sludge confirmed its presence by energy dispersive system (EDS) analysis using a scanning electron microscopy (SEM).
\end{abstract}

Keywords: Sulfur; Sewage sludge; Sulfur isotopes; Contamination. 


\section{INTRODUÇÃO}

Diversas amostras de lodo de esgoto coletadas na Estação de Tratamento de Esgoto - ETE Barueri exibem concentrações elevadas de enxofre e surgimento de enxofre nativo quando micronizadas. Sua presença tem promovido diversas linhas especulativas para explicar a sua origem. Na natureza o enxofre ocorre de modo mais comum como resultado das emissões vulcânicas (principalmente como $\mathrm{SO}_{2}$ ), de aerossóis de sais marinhos (como $\mathrm{SO}_{4}{ }^{2-}$ ), do metabolismo do fitoplâncton marinho (DMS - sulfeto de dimetila), das queimadas florestais e da decomposição de matéria orgânica. O ciclo do enxofre foi alterado significativamente como resultado das atividades humanas de uso e ocupação do solo e pela queima de combustíveis fósseis. Stumm e Morgan (1995) relacionam essa intervenção antrópica ao desequilíbrio na transferência de enxofre proveniente do ambiente marinho para a atmosfera. O fluxo de enxofre entre a atmosfera continental e oceânica aumentou de $10 \mathrm{Tg}\left(10.10^{12} \mathrm{~g}\right)$ de enxofre/ano para $61 \mathrm{Tg}$ de enxofre/ano. Segundo Andrews et al. (1996), a deposição de enxofre proveniente da atmosfera nos oceanos e continentes aumentou em aproximadamente 25\% e 163\%, respectivamente. A capacidade de tamponamento e a grande quantidade de íons sulfato da água do mar neutralizam o impacto desse aumento sobre o ambiente marinho, aspecto esse que não ocorre nos ambientes terrestres, solo e águas doces, cujos efeitos são mais significativos.

A presença de enxofre em lodos de esgoto encontra parte de sua origem creditada à vinculação com fezes, fonte de compostos de proteínas (Jordão e Pessoa, 1995; Chagas, 2000; Bettiol e Camargo, 2004), como a tiamina, que produz, em condições redutoras, gás sulfídrico $\left(\mathrm{H}_{2} \mathrm{~S}\right)$, de odor característico, e das águas de abastecimento, principalmente sob a forma de sulfatos e sulfetos inorgânicos e surfactantes, alquil-sulfonado-lineares, presentes nos detergentes sintéticos biodegradáveis (Jordão e Pessoa, 1995). Neste ambiente, o enxofre está em constante transformação envolvendo reações de oxi-redução promovidas por microrganismos (Tsutiya, 2002). O ciclo biológico do enxofre em águas residuárias ricas em sulfato baseia-se na atividade das bactérias redutoras de sulfato a sulfeto (Molwantwa et al., 2004). A composição da água residuária e a disponibilidade de oxigênio no sistema definem os grupos de microrganismos no processo de tratamento.

O sistema de lodos ativados da ETE Barueri emprega tanques de aeração e digestores anaeróbios para o tratamento de esgoto. Nessas condições, microrganismos aeróbios e bactérias heterótrofas promovem a oxidação da matéria orgânica (Teixeira et al., 2002). Outras variedades são capazes de oxidar sulfetos com a formação de grânulos de enxofre elementar. Essas bactérias podem ser en- contradas na estrutura dos flocos ou livres (Molwantwa et al., 2004). Bactérias presentes em biodigestores anaeróbios removem o hidrogênio e reduzem o íon sulfato. Espécies bacterianas presentes em biorreatores anaeróbios têm a capacidade de degradar detergentes como alquilbenzenos sulfonados lineares e ramificados.

O tratamento anaeróbio do lodo primário em estações de tratamento de esgoto esbarra na presença de metais pesados. Esses representam uma das principais causas de problemas que inviabilizam o tratamento anaeróbio por representarem importante fator de toxicidade para as bactérias metanogênicas responsáveis por esse processo (Foresti et al., 1999). O controle dessa toxicidade em um biodigestor através da precipitação desses metais pesados como sulfeto foi verificado e descrito por Lawrence e McCarty (1965) e Masselli et. al. (1967). Na década de 80, uma patente sueca descreveu o cultivo de bactérias em presença de uma solução nutritiva, fonte de sulfato (Hallberg, 1980 apud Rizzo e Leite, 2004). Neste mesmo período a empresa Shell Research (Rizzo e Leite, 2004) identificou a redução anaeróbia de sulfato como o processo mais viável economicamente para a remoção de metais pesados em efluentes, quando comparado à troca iônica e extração com membranas. Na década de 90, em uma das indústrias pertencentes ao grupo Siemens (Alemanha), foi implantada uma unidade de tratamento biológico de efluentes contendo metais pesados empregando o processo METEX proposto por Morper e Furst (1991). Nesse, ocorria uma etapa de controle do pH para que a precipitação dos sulfetos metálicos fosse favorecida. Além do efluente, o biorreator era alimentado por compostos orgânicos, amônia e sulfato, subsidiando o desenvolvimento das bactérias responsáveis pela redução de sulfato a sulfeto. Nesse empreendimento o produto utilizado como fonte de matéria orgânica e amônia foi coletado em uma estação de tratamento de esgoto sanitário municipal. Esse tratamento mostrou-se eficiente tanto para a remoção de metais pesados quanto para sulfato.

Os atuais métodos químicos são incapazes de distinguir o $\mathrm{SO}_{2}$ e $\mathrm{SO}_{4}^{2-}$ de origem antrópica do natural. Principalmente considerando amostras complexas como é o caso do lodo de esgoto. Entretanto, isótopos estáveis podem ser utilizados para estudos ambientais como traçadores de processos ou das fontes geradoras. Essa técnica baseia-se na medida da razão isotópica de um mesmo elemento, em particular do oxigênio ${ }^{18} \mathrm{O} /{ }^{16} \mathrm{O}$ e ${ }^{17} \mathrm{O} /{ }^{16} \mathrm{O}$ e do enxofre ${ }^{34} \mathrm{~S} /{ }^{32} \mathrm{~S}$, expressa por $\delta^{34} \mathrm{~S}$. Se esse valor for maior do que 20\% CDT (Canyon Diablo Troilite, amostra padrão de sulfeto de ferro proveniente do meteorito Canyon Diablo, igual a 0,0450), então, a origem do enxofre é essencialmente do dimetilsulfeto - DMS marinho produzido pelo fitoplâncton (Charlson e Wigley, 1994). Para valores que variam de 0 a $10 \%$ CDT a origem do enxofre é atribuí- 
da à queima de combustíveis fósseis. Valores intermediários corresponderiam a ambas as fontes de enxofre.

No presente trabalho objetivou-se determinar as possíveis origens do enxofre presente no lodo da ETE de Barueri, por meio de análise das correlações entre suas concentrações e as de outros elementos químicos.

\section{ÁREA DE ESTUDO}

A ETE de Barueri está em operação desde 1988 e localiza-se no município de Barueri, estado de São Paulo. Segundo a Companhia de Saneamento Básico do Estado de São Paulo (SABESP), a ETE Barueri atende a uma população de mais de 6.000.000 habitantes de grande parte da zona oeste, partes da zona norte, sul, centro e pequena parte da zona leste da cidade de São Paulo e dos municípios de Jandira, Itapevi, Barueri, Carapicuíba, Osasco, Taboão da Serra e parcialmente Cotia e Embu. Projetada inicialmente para uma vazão máxima de $63 \mathrm{~m} 3 / \mathrm{s}$, apresenta atualmente esse valor reduzido para $24 \mathrm{~m}^{3} / \mathrm{s}$, segundo a revisão do Plano Diretor de 1999. Sua capacidade real atual de tratamento é de $9,5 \mathrm{~m}^{3} / \mathrm{s}$ com a produção diária de $228 \mathrm{t}$ de lodo desidratado. Atualmente, o lodo é encaminhado para o Aterro Bandeirantes, às margens da Rodovia dos Bandeirantes, km 26. Seus efluentes são lançados no rio Tietê que nesse trecho é classificado como corpo receptor de classe 4, segundo o Decreto Estadual 10.755/77.

O tipo da planta de tratamento é o de lodo ativado convencional com eficiência de 90\% de remoção da carga orgânica medida em DBO. No ano de 2000 houve alteração dos produtos químicos para o condicionamento do lodo de esgoto, mantendo o cloreto férrico, mas, passou-se a utilizar, ao invés de cal, um polímero orgânico catiônico sintético a base de acrilamida. Em ambos os casos o lodo resulta do tratamento anaeróbio e do desaguamento feito por filtro prensa de placas. Essa alteração resultou num menor percentual de sólidos do lodo final, passando de 38 para 33\%.

\section{MATERIAL E MÉTODOS}

\section{Coleta e preparação das amostras}

As amostras de lodo de esgoto analisadas e apresentadas nesse trabalho, foram obtidas semanalmente na ETE Barueri em dois períodos distintos: 16 amostras no período de maior precipitação pluviométrica na área (entre os dias 29/11/02 a 25/03/03) e 14 amostras no período de baixa precipitação pluviométrica (entre 17/06/03 a 12/10/03). Em cada uma das coletas foi obtida amostra da pilha existente no pátio da ETE produzido no dia da própria coleta. Essa amostra foi composta por pelo menos 20 subamostras, retiradas aleatoriamente ao redor da pilha de lodo, desde o topo até a base. As amostras, coletadas com espátula, foram homogeneizadas e armazenadas em sacos plásticos de polietileno congeladas, posteriormente autoclavadas e encaminhadas para caracterização química.

A autoclavagem, realizada pela Embrapa Meio Ambiente, sediada em Jaguariúna, SP, consistiu no tratamento dessas amostras à temperatura de $120^{\circ} \mathrm{C}$ e à pressão de $1 \mathrm{~atm}$, pelo período de $1 \mathrm{~h}$, por duas vezes, em diferentes dias. Após a autoclavagem as amostras, em estado pastoso, foram homogeneizadas e separadas em duas subamostras sendo uma delas congelada. As amostras foram pesadas úmidas e colocadas para secar ao ar em local que não oferecia risco de contaminação de outras amostras. A pesagem das amostras, depois de secas, permitiu a determinação do percentual de umidade. Estas formaram agregados de difícil moagem, razão pela qual necessitaram ser desagregadas em almofariz e pistilo de ágata antes de serem colocadas em moinho de anéis, também de ágata, por 15 min. O pó fino resultante da moagem foi utilizado nas análises químicas. Essa etapa foi efetuada no - Laboratório de Tratamento de Amostras (LTA) do Instituto de Geociências da USP (IGc/USP).

\section{Análises químicas e isotópicas}

A determinação da concentração do enxofre foi efetuada por análise térmica da amostra seca à $1.350^{\circ} \mathrm{C}$ utilizando o equipamento da LECO Instruments, modelo SC - 432. Para a determinação dos metais pesados foi empregada a fluorescência de raios X (FRX) (Moraes, 2003; West et. al., 1995) por ser uma técnica analítica rápida, confiável e com limites de detecção que, embora superiores aos das análises por ICP-OES, são adequados à determinação das concentrações dos elementos químicos presentes nessas amostras. Porém, na preparação das pastilhas fundidas, observou-se o ataque da amostra às paredes do cadinho, razão pela qual se optou realizar somente a determinação dos metais pesados por essa técnica, com emprego de pastilhas prensadas.

O processo denominado micronização foi necessário à preparação dessas pastilhas. Nesse caso, a amostra foi submetida à moagem com pequenos cilindros de ágata existentes no interior de um frasco de polietileno, em meio álcool etílico hidratado. A suspensão resultante foi colocada para secar em estufa à $60^{\circ} \mathrm{C}$. À massa da amostra seca foi adicionada parafina em pó. A mistura foi homogeneizada, prensada e a pastilha obtida com 35 mm de diâmetro e aproximadamente $5 \mathrm{~mm}$ de espessura. O equipamento de FRX utilizado foi da marca Philips, modelo PW2400, do Laboratório de Fluorescência de Raios X do Departamento de Mineralogia e Geotectônica do IGc/USP.

Os teores dos demais elementos foram determinados por ICP-OES, modelo 3419 da ARL, no Laboratório de Química e ICP do IGc/USP. Utilizou-se o método da fusão 
alcalina com mistura de meta e tetraborato de lítio. Esse método oferece a vantagem sobre o ataque ácido nas análises, pois mantém o silício em solução, garante a dissolução de minerais refratários como zircão, cromita, berilo, monazita, possibilitando a determinação quantitativa dos elementos traços como $\mathrm{Zr}$, Cr e Be, além de atenuar os possíveis efeitos de matriz (Janasi et. al., 1996). Os limites de detecção (LD) e quantificação (LQ) para os elementos químicos em ambos os métodos encontram-se nas Tabelas 1 e 2, juntamente com os resultados analíticos. Como as amostras de lodo de esgoto ficavam muito aderidas às paredes do cadinho, com aparente oleosidade que impedia sua transferência total, optou-se por pesar o fundente em cadinho de porcelana e transferir metade de seu conteúdo para o cadinho de grafite de maneira que cobrisse totalmente o fundo. Em seguida, a amostra de lodo de esgoto foi acrescentada com cuidado para que não tocasse as paredes do cadinho, nem tão pouco ultrapassasse a massa desejada de $0,2500 \pm 0,0001 \mathrm{~g}$. O restante do fundente foi transferido de maneira a cobrir totalmente a amostra. Duas das amostras que puderam ser transferidas quantitativamente pelo método tradicional foram repetidas pelo novo procedimento e não apresentaram variação significativa dos resultados analíticos. A modificação da técnica trouxe a vantagem de reduzir consideravelmente os odores durante a queima a $1.000^{\circ} \mathrm{C}$ do processo de fusão.

As mesmas amostras foram encaminhadas para o Laboratório de Solos e Nutrição de Plantas da Escola Superior de Agricultura Luiz de Queiroz - ESALQ/USP/Piracicaba para as determinações do $\mathrm{pH}$ em $\mathrm{CaCl}_{2}$, dos teores de matéria orgânica total, matéria orgânica compostável, carbono total e orgânico, nitrogênio total e resíduo mineral total.

Os teores de sulfato foram obtidos para algumas das amostras de lodo de esgoto extraídos com água destilada à $100^{\circ} \mathrm{C}$, por $3 \mathrm{~h}$, sob refluxo (Ros et al., 2006) e determinados por cromatografia de íons, DIONEX ICS 90, no Centro de Pesquisas de Águas Subterrâneas - CEPAS, IGc/USP.

Para a determinação do $\delta^{34} \mathrm{~S}$ foram utilizados extratos da fração orgânica presente nas amostras de lodo de esgoto, uma vez que a precipitação do $\mathrm{BaSO}_{4}$ não foi possível para o extrato contendo a fração solúvel com água destilada. Foram utilizados $2 \mathrm{~g}$ da amostra para $40 \mathrm{~mL}$ da solução extratora ( $\left.\mathrm{NaOH} 0,5 \mathrm{M} / \mathrm{Na}_{4} \mathrm{P}_{2} \mathrm{O}_{7} 0,1 \mathrm{M}\right)$, sob agitação por 24 h, centrifugado por 20 min a 6.000 rpm, filtrado à vácuo com filtro de fibra de vidro (GF/C) para obtenção do $1^{\circ}$ extrato. Para a $2^{a}$ extração utilizou-se $20 \mathrm{~mL}$ da solução extratora sob agitação por $12 \mathrm{~h}$ e a $3^{\mathrm{a}}$ extração com o mesmo volume, porém com o tempo de agitação de 6 h. Os extratos foram juntados e avolumados com a solução extratora para $100 \mathrm{~mL}$.
O volume de $20 \mathrm{~mL}$ de extrato foi transferido para uma cápsula de porcelana e digerido com 12 mL de $\mathrm{HNO}_{3}$ concentrado e $4 \mathrm{~mL}$ de $\mathrm{H}_{2} \mathrm{O}_{2}$, à temperatura variando entre 70 e $80^{\circ} \mathrm{C}$, por $24 \mathrm{~h}$. Ao extrato digerido foi acrescentada água destilada, transferido para tubo de centrífuga de $50 \mathrm{~mL}$, submetido a $5.000 \mathrm{rpm}$ por $10 \mathrm{~min}$ e filtrado em GF/C. Ao filtrado foi adicionada solução de $\mathrm{NaOH}$ $0,01 \mathrm{M}$, gota a gota até atingir $\mathrm{pH}$ entre 5 e 6 . Adicionouse $\mathrm{BaCl}_{2}$ para obter-se o precipitado $\mathrm{BaSO}_{4}$. As amostras obtidas foram enviadas para determinação da razão isotópica $\delta^{34}$ S no Environmental Isotope Laboratory, Department of Geosciences, University of Arizona. $\mathrm{O} \delta^{34} \mathrm{~S}$ foi medido para o gás $\mathrm{SO}_{2}$ com a utilização de um espectrômetro de massa (ThermoQuest Finnigan Delta Plus XL). Para a obtenção do $\mathrm{SO}_{2}$, as amostras foram queimadas a $1.030^{\circ} \mathrm{C}$ com a presença de $\mathrm{O}_{2}$ e $\mathrm{V}_{2} \mathrm{O}_{5}$, utilizando analisador elementar (Costech) acoplado ao espectrômetro. Os padrões utilizados foram OGS-1 e NBS123 e precisão estimada de \pm 0,15 (1 sigma).

\section{Análises por difração de raios $X$ e por microscopia eletrônica de varredura (MEV)}

Investigou-se a natureza dos cristais presentes nas amostras micronizadas de lodo, primeiramente com o auxílio da difração de raios X (DRX). Para essa análise, os cristais foram isolados da matriz do lodo de esgoto e submetidos ao difratômetro de pó Siemens, modelo D5000. Os cristais também foram observados, sobre a matriz do lodo de esgoto e isolados desta, com recobrimento de ouro, ao MEV - Microscópio Eletrônico de Varredura LEO 440I, do Laboratório de Microscopia Eletrônica do IGc/ USP. Foram realizadas análises químicas pontuais com o auxílio do Espectrômetro de Energia Dispersiva de raios X da Oxford. Observaram-se também esses cristais, isolados da matriz, ao microscópio óptico.

\section{Análises estatísticas}

Os fatores de correlação de Pearson foram utilizados com o intuito de avaliar as possíveis associações entre o enxofre e os demais elementos presentes nas amostras de lodo de esgoto (Tabela 1). Foram consideradas como correlações significativamente diferentes de zero, aquelas que possuem valores menores que menos 0,50 ou valores maiores que 0,50 para o período de maior precipitação pluviométrica e as que possuem valores menores que menos 0,53 ou valores maiores que 0,53 para o período de menor precipitação. Para a obtenção desses valores críticos foi utilizado o teste de correlação de Pearson (Bussab e Morettin, 2006) que considera o tamanho da amostra e a distribuição t-student, com um nível de significância de 5\%. 
Outros testes foram aplicados aos conjuntos de resultados para as concentrações do enxofre e demais elementos nas amostras coletadas nos dois períodos pluviométricos. A função de autocorrelação esta entre as metodologias utilizadas para ajustar modelos de séries temporais. A autocorrelação é uma medida do nível de semelhança entre uma variável e sua anterior num intervalo de tempo. Informa o quanto o valor de uma realização de uma variável aleatória é capaz de influenciar suas vizinhas ao longo do tempo. Seus valores variam entre 1 (correlação perfeita) e menos 1 (anticorrelação), sendo que o valor zero indica ausência de correlação.

Como neste estudo o universo amostral é pequeno, 16 amostras para o período de maior precipitação pluviométrica e 14 para o de menor precipitação, um teste não paramétrico foi utilizado (Wilcoxon Mann-Whitney descrito em Conover, 2001). Pareceu ser o mais apropriado para verificar a suposição de normalidade e indicar se as concentrações são iguais ou diferentes para os períodos. As suposições do teste são: amostras independentes, variáveis no mínimo ordenáveis e poucos empates. As hipóteses a serem testadas são: $\mathrm{H}_{0}$ : a concentração da variável não é diferente para ambos os períodos e $\mathrm{H}_{\mathrm{a}}$ : a concentração da variável não é a mesma para os diferentes períodos. O teste de Wilcoxon calcula um valor $\underline{\boldsymbol{S}}$ ao qual está associado um valor de probabilidade (Pr). O programa existente no GMC software calcula automaticamente a probabilidade. Se os valores de Pr forem maiores que o módulo de $\mathbf{t}$ 5\% ou 0,05 , a igualdade se confirma. O t é referente ao ponto de corte de 95\% utilizado para o teste de Wilcoxon.

\section{RESULTADOS E DISCUSSÃO}

A determinação dos teores de elementos menores como cobre $(\mathrm{Cu})$, cromo $(\mathrm{Cr})$, ferro $(\mathrm{Fe})$, níquel $(\mathrm{Ni})$ e zinco (Zn) e elementos maiores associados como silício, alumínio, ferro e outros (Tabelas 1 e 2), presentes nas amostras de lodo de esgoto coletadas na ETE de Barueri indicaram claramente que o fator sazonalidade interfere diretamente na concentração desses diversos elementos, exibindo oscilação que se coaduna com soluções mais diluídas e soluções mais concentradas no que diz respeito a qualidade do lodo de esgoto. Dentre os elementos analisados, além dos metais mencionados, o lodo da ETE Barueri apresentou elevados teores de enxofre e cristais contendo esse elemento, formado sobre amostras micronizadas e secas, durante a preparação das pastilhas prensadas para determinação da concentração de elementos traços por fluorescência de raios-X. A presença de enxofre em lodo de esgoto pode tornar possível o controle da toxicidade causada por metais pesados às bactérias metanogênicas, responsáveis pelo processo de tratamento anaeróbio de lodo primá- rio. Lawrence e McCarty (1965) e Masselli et al. (1967) verificaram ser possível o controle dessa toxicidade em um biodigestor através da precipitação desses metais pesados como sulfetos. A distribuição e comportamento das precipitações pluviais para a cidade de São Paulo apresenta de modo geral distinção de dois macroperíodos de chuva, houve tentativa de se identificar o efeito dessa sazonalidade sobre as concentrações dos metais pesados no lodo de esgoto da ETE Barueri. Segundo relatórios de 2000 a 2005 do Instituto Astronômico e Geofísico da Universidade de São Paulo (IAG), ocorrem dois períodos distintos pluviométricos, um de menor e outro de maior precipitação compreendendo, respectivamente, os meses de abril a setembro e de outubro a março. Observa-se, ainda, que durante esses macroperíodos aconteceram variações eventuais como picos de precipitação nos meses de maio e julho de 2001 e 2002 e baixa pluviosidade nos meses de janeiro de 2000 e 2001, fevereiro, outubro e novembro de 2003. Por essa razão considerou-se as amostras ETE13Q e ETE14Q (Tabela 2), coletadas no mês de outubro de 2003, pertencentes ao período seco. Os resultados obtidos de diversas amostras coletadas nesses períodos com as respectivas concentrações dos elementos maiores, obtidas por espectroscopia de emissão atômica por injeção de plasma induzido (ICPOES), dos elementos traços por fluorescência de raios-X (FRX) e da análise térmica para o enxofre (LECO) podem ser visualizadas nas Tabelas 1 e 2 .

O teste não-paramétrico (fatores LD e LQ das Tabelas 1 e 2) aplicado para confirmar ou rejeitar a igualdade entre as médias de cada espécie química de interesse indicaram que as variáveis para os compostos e elementos $\mathrm{Fe}_{2} \mathrm{O}_{3}$, $\mathrm{P}_{2} \mathrm{O}_{5}, \mathrm{MnO}, \mathrm{Cr}, \mathrm{Cu}, \mathrm{Pb}$ e $\mathrm{Zr}$ possuíam concentrações semelhantes em ambos os períodos pluviométricos. Por outro lado, todos os demais elementos analisados apresentaram variação significativa das concentrações associada ao fator sazonalidade (Tabelas 1 e 2). A amostra ETE 12Q apresenta comportamento anômalo, com seus teores de alumínio, cálcio, fósforo, titânio, cromo, cobre enxofre e zinco, inferiores às demais amostras do mesmo período climáti$\mathrm{co}$, e com percentuais de silício $\left(\mathrm{SiO}_{2}\right)$ superiores. No entanto, essa anomalia vem corroborar com a ideia de que na produção do lodo de esgoto, não se podem controlar eventuais alterações acentuadas da sua composição química.

Elementos associados a minerais clásticos secundários e detríticos, aparecem em concentrações maiores no período chuvoso. Assim, as concentrações maiores para o silício, alumínio, sódio e potássio podem estar associados à presença mais significativa de quartzo e argilominerais oriundos de solos erodidos no período de maior precipitação pluviométrica. O titânio pode ser associado à presença de ilmenita, o lantânio à monazita e o bário à barita, biotita e muscovita. Os elementos $\mathrm{S}, \mathrm{Ca}, \mathrm{Ni}$, Cr e principalmente 


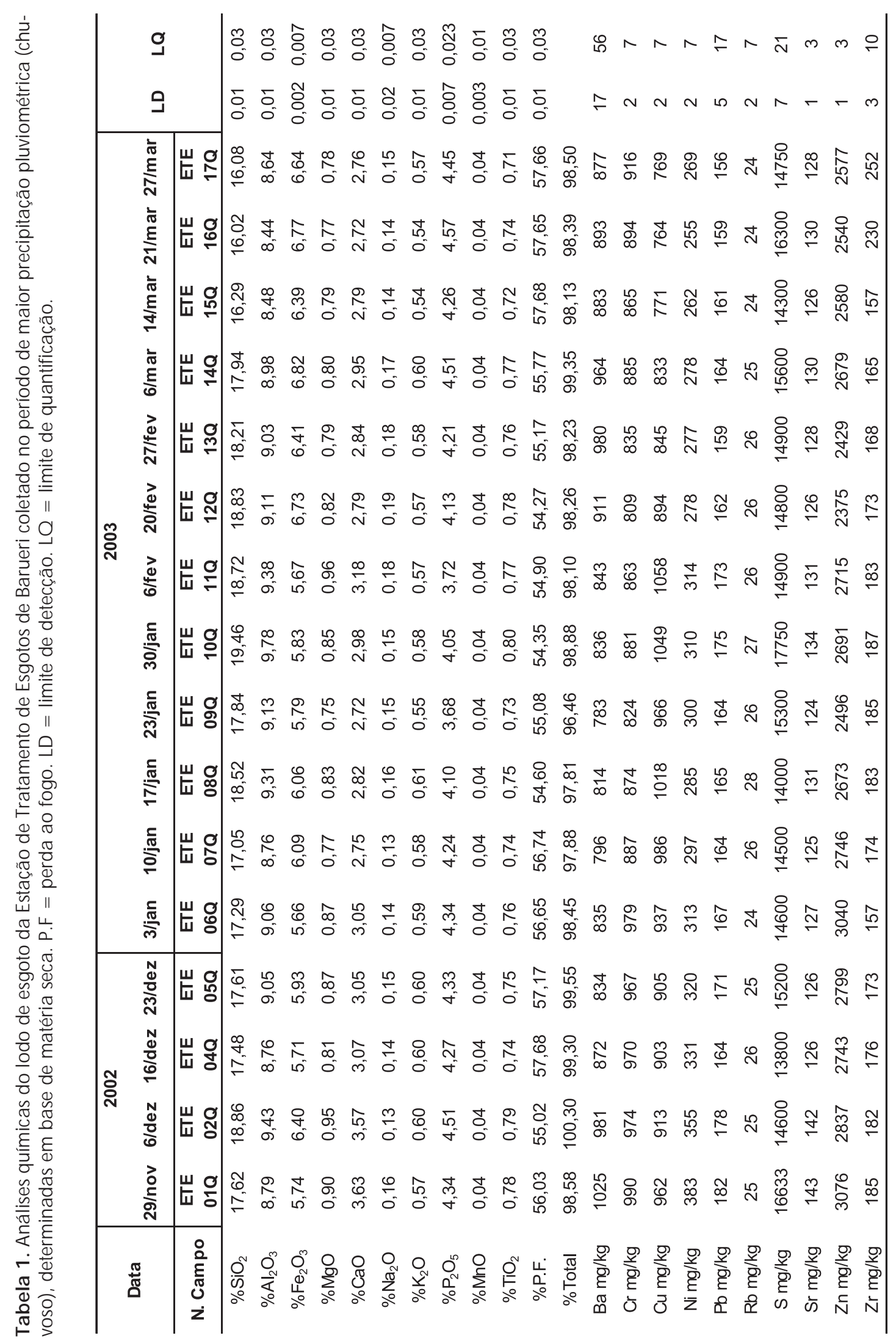




\begin{tabular}{|c|c|}
\hline g & 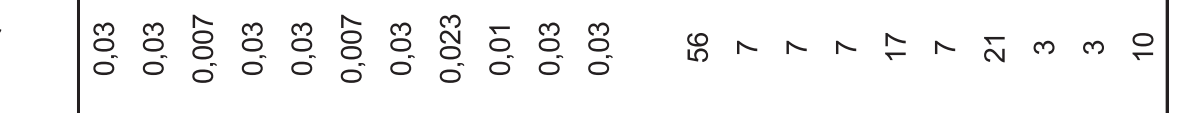 \\
\hline د & 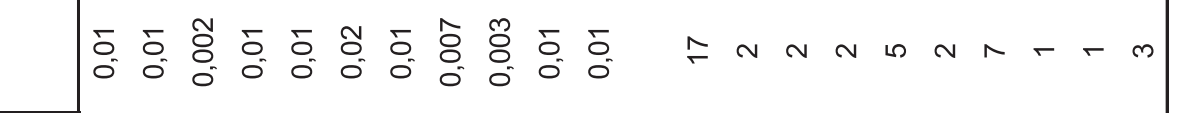 \\
\hline & 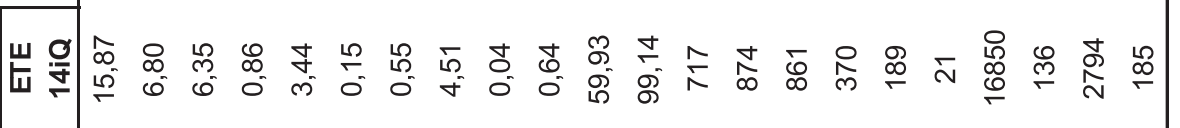 \\
\hline & 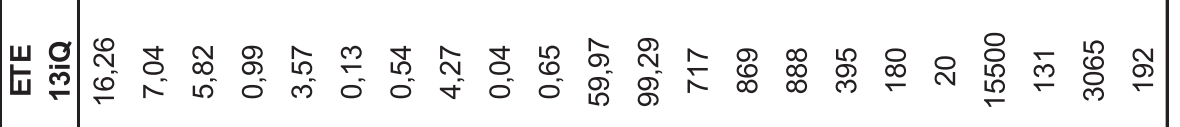 \\
\hline & 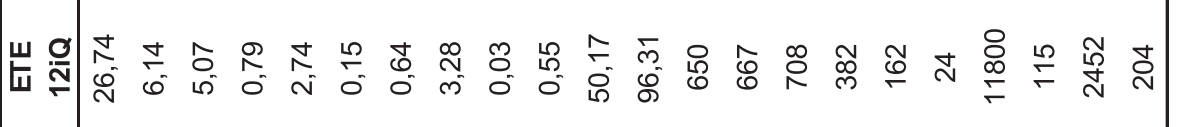 \\
\hline & 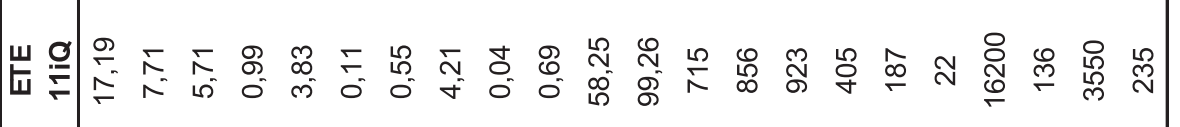 \\
\hline & 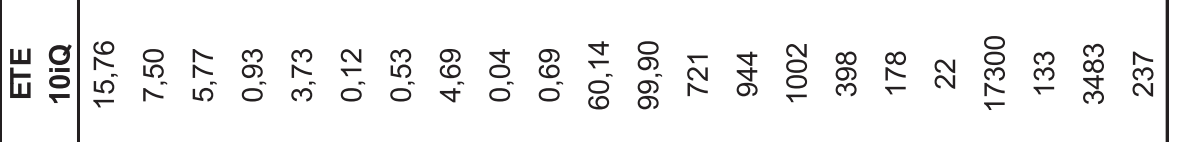 \\
\hline & 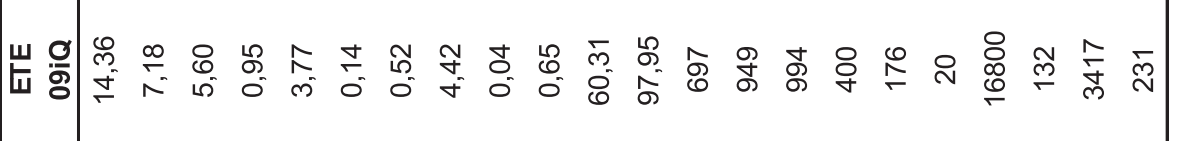 \\
\hline & 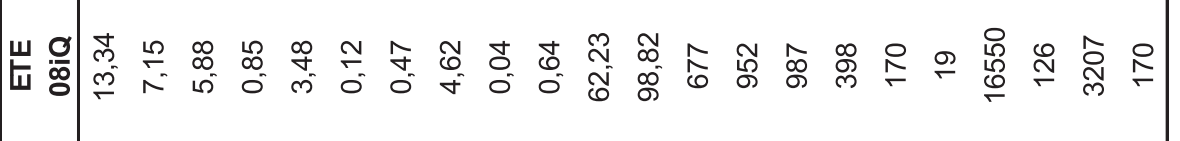 \\
\hline & 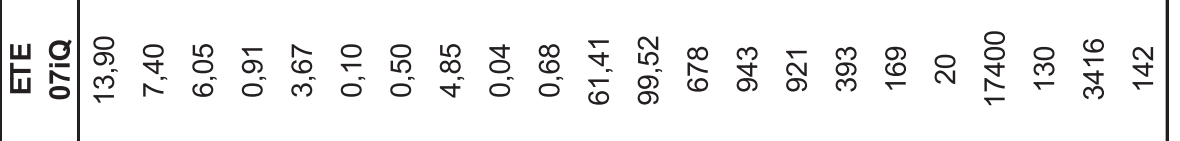 \\
\hline & 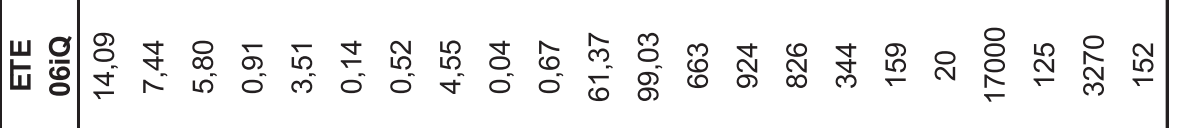 \\
\hline & 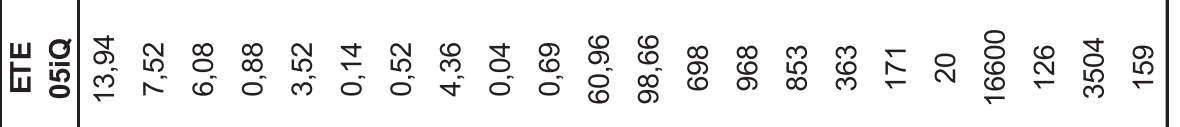 \\
\hline & 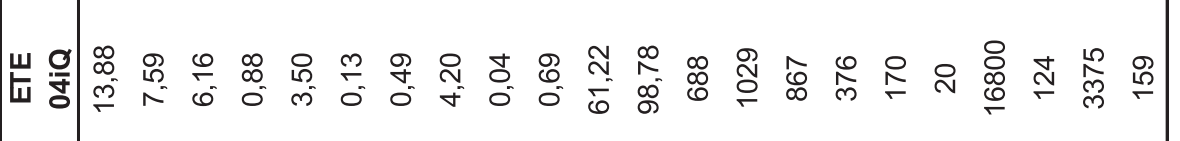 \\
\hline & 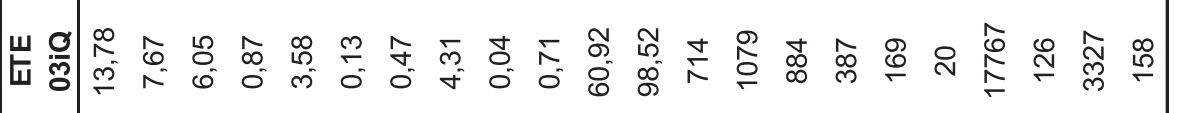 \\
\hline & 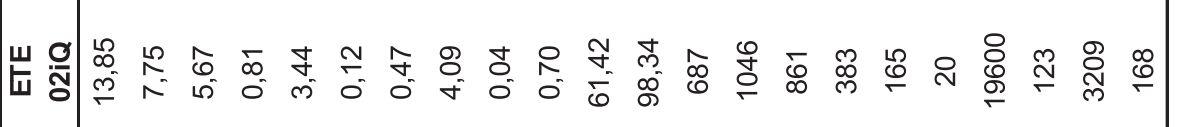 \\
\hline & 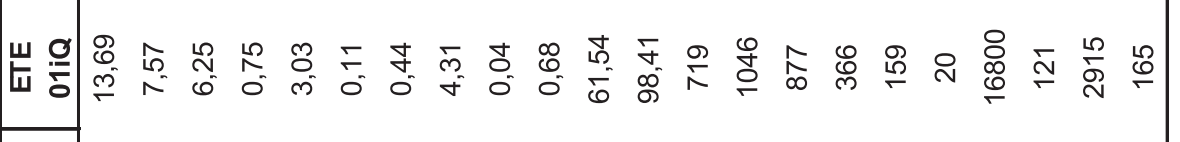 \\
\hline & \\
\hline
\end{tabular}


o Zn têm suas concentrações reduzidas pelo efeito de diluição, diferentemente do cobre.

As correlações entre as concentrações dos metais pesados e a precipitação pluviométrica indicam que, no período seco, os metais zinco e cromo são inversamente correlacionados com a pluviosidade, ou seja, quanto menor a precipitação pluviométrica, maior suas concentrações. Observa-se ainda que o cobre é o único dos metais a apresentar correlação entre o aumento da sua concentração em função do aumento da precipitação pluviométrica.

As variações entre as concentrações máximas e mínimas do cromo e do zinco num mesmo período climático são significativas. Analisados sob a óptica da Resolução CONAMA n ${ }^{\circ} 359$ (2006), os teores máximos de cromo (1079 mg/kg) e zinco (3550 mg/kg) no período seco e somente do zinco no período chuvoso (3076 mg/kg) excederam aos limites impostos por essa resolução. As concentrações de níquel no período seco estiveram muito próximas à máxima permitida pela legislação considerando esse tipo de resíduo como resíduo de classe I.

As concentrações de enxofre (S) não apresentaram autocorrelação significante nos dois períodos, como se verifica na Figura 1. Essa constatação indica serem as observações dessas séries não correlacionáveis e, sob a suposição de normalidade, independentes.

O teste não paramétrico de Wilcoxon, com o nível de significância de 5\%, mostrou que as concentrações de enxofre são diferentes para cada período, assim como de níquel, zinco, alumínio, silício, cálcio, magnésio, sódio, potássio e titânio. Os percentuais de matéria orgânica e volátil, expressos pelo percentual de perda ao fogo (P.F.) também são diferentes nos períodos (Tabela 3).
A amostra ETE 12iQ apresenta comportamento anômalo, com seus teores de alumínio, cálcio, fósforo, titânio, cromo, cobre enxofre e zinco menores que as demais amostras do mesmo período, não sendo identificada sua causa (Tabela 2). Os percentuais de $\mathrm{SiO}_{2}, \mathrm{Al}_{2} \mathrm{O}_{3}, \mathrm{TiO}_{2}$ e os teores de zircônio são maiores no período de maior precipitação pluviométrica e estão relacionados ao maior aporte de material clástico e detrítico carreado pelas chuvas, quartzo, argilominerais e ilmenita (Tabelas 1 e 2).

Os coeficientes amostrais de Pearson permitiram constatar que no período de menor precipitação pluviométrica as variáveis são mais correlacionadas que no período de maior precipitação pluviométrica (Tabela 4). O enxofre presente no lodo de esgoto no período de menor precipitação pluviométrica parece estar associado à matéria orgânica, compostos orgânicos sulfonados, como os surfactantes presentes nos detergentes e ao resíduo mineral solúvel sob a forma de sulfato de alumínio, ferro, cálcio, cromo e zinco, e talvez cobre. Dados da Síntese de Informações Operacionais dos Sistemas de Tratamento de Esgotos da Região Metropolitana de São Paulo (RMSP), período janeiro a dezembro de 2002, revelaram que os teores de surfactantes presentes no esgoto bruto que adentra a ETE Barueri são em média 12 mg/L e 28 mg/L, respectivamente, para os períodos de maior precipitação pluviométrica e de menor precipitação pluviométrica.

Os valores $\delta^{34} \mathrm{~S}$ obtidos para enxofre precipitado sob a forma de sulfato extraído das amostras de lodo de esgoto 08iQ, 12iQ e Jagua foram, respectivamente, 9,8\%, 9,5\% e $8,4 \%$. Os dados obtidos nesse trabalho como indicativo de origem e proveniência do enxofre determinado, podem ser correlacionados com valores encontrados na literatura para

Figura 1. Funções de autocorrelação da variável S do lodo de esgoto da Estação de Tratamento de Esgoto de Barueri para os períodos seco e chuvoso.

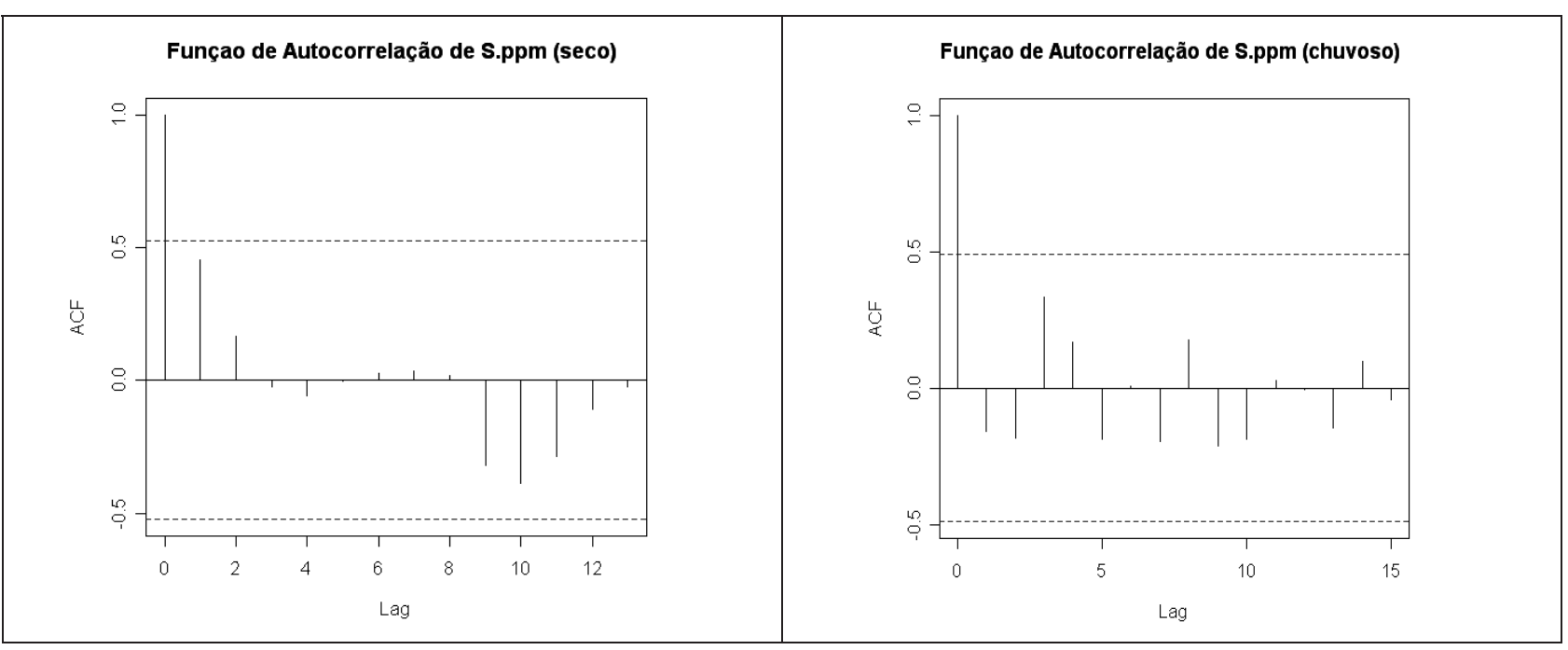


Tabela 3. Resultados do teste não paramétrico de Wilcoxon Mann-Whitney para verificar a igualdade entre as concentrações dos elementos químicos do lodo de esgoto nos dois períodos climáticos (chuvoso e seco).

\begin{tabular}{|c|c|c|c|}
\hline \multirow{2}{*}{ Variáveis } & \multicolumn{2}{|c|}{ Wilcoxon Test } & \multirow{2}{*}{$\begin{array}{c}\text { Conclusão } \\
\text { a } 5 \%\end{array}$} \\
\hline & $\mathbf{S}$ & $\operatorname{Pr}>|\mathbf{t}|$ & \\
\hline $\mathrm{Cr}$ & 249,5 & 0,1937 & $=$ \\
\hline $\mathrm{Cu}$ & 200,0 & 0,4982 & $=$ \\
\hline $\mathrm{Ni}$ & 321,5 & 0,0002 & $\neq$ \\
\hline $\mathrm{Pb}$ & 254,0 & 0,1281 & $=$ \\
\hline$S$ & 295,0 & 0,0013 & $\neq$ \\
\hline $\mathrm{Zn}$ & 308,0 & 0,0008 & $\neq$ \\
\hline $\mathrm{Zr}$ & 206,0 & 0,6654 & $=$ \\
\hline $\mathrm{Al}_{2} \mathrm{O}_{3}$ & 105,0 & $<0,0001$ & $\neq$ \\
\hline $\mathrm{CaO}$ & 294,5 & 0,0033 & $\neq$ \\
\hline $\mathrm{Fe}_{2} \mathrm{O}_{3}$ & 178,0 & 0,1202 & $=$ \\
\hline $\mathrm{K}_{2} \mathrm{O}$ & 127,0 & 0,0008 & $\neq$ \\
\hline $\mathrm{MgO}$ & 266,0 & 0,0427 & $\neq$ \\
\hline $\mathrm{MnO}$ & 209,0 & 0,3245 & $=$ \\
\hline $\mathrm{Na}_{2} \mathrm{O}$ & 136,0 & 0,0002 & $\neq$ \\
\hline $\mathrm{P}_{2} \mathrm{O}_{5}$ & 246,0 & 0,2453 & $=$ \\
\hline P.F. & 313,0 & 0,0004 & $\neq$ \\
\hline $\mathrm{SiO}_{2}$ & 127,0 & 0,0008 & $\neq$ \\
\hline $\mathrm{TiO}_{2}$ & 105,5 & 0,0001 & $\neq$ \\
\hline
\end{tabular}

diferentes fontes possíveis de enxofre, naturais ou antrópicas. Porém, os valores $\delta^{34} \mathrm{~S}$ podem também ser resultantes da contribuição de duas ou mais fontes de enxofre (Krouse e Grinenko, 1991) o que resulta em valores intermediários. Cravotta (1997) analisou amostras de estercos de diferentes animais, fertilizantes, esgoto e fossas sépticas para identificar as possíveis fontes de enxofre nas águas da bacia do Lower Susquehanna, Pennsylvania. As médias dos valores de $\delta^{34} \mathrm{~S}$ para amostras de fossas sépticas mostraram ser maiores na fração solúvel que na particulada e no lodo, 9,20, 3,91 e 1,00\%, respectivamente. Os valores de $\delta^{34} S$ para as mesmas frações obtidas para amostras de estação de tratamento de esgoto foram 4,97, 4,78 e 2,47\%. Para os fertilizantes, o referido autor verificou $\delta^{34} \mathrm{~S}$ médio de $8,22 \%$, embora com desvio padrão bastante elevado $(6,61)$. O enxofre encontrado nas fossas sépticas está relacionado à presença das fezes humanas e surfactantes, enquanto que sua origem no esgoto coletado numa estação de tratamento municipal também recebe o aporte de efluentes industriais e solo (fertilizantes) carreado pelas águas pluviais e fluviais.

Há também a possibilidade da contribuição do enxofre de origem atmosférica. Leal et al. (2004) destacaram a sig-
Tabela 4. Coeficientes de correlação amostral de Pearson para o enxofre lodo de esgoto da Estação de Tratamento de Esgoto de Barueri com relação aos demais elementos aqui analisados para os períodos seco e chuvoso.

\begin{tabular}{ccc}
\hline \multirow{2}{*}{ Período } & \multicolumn{2}{c}{$\mathbf{S}(\mathrm{mg} / \mathrm{Kg})$} \\
\cline { 2 - 3 } & $\mathrm{Seco}$ & Chuvoso \\
\hline $\mathrm{SiO}_{2}(\%)$ & $-0,77$ & $-0,10$ \\
$\mathrm{Al}_{2} \mathrm{O}_{3}(\%)$ & 0,88 & $-0,04$ \\
$\mathrm{Fe}_{2} \mathrm{O}_{3}(\%)$ & 0,44 & $-0,25$ \\
$\mathrm{MgO}(\%)$ & $-0,01$ & 0,01 \\
$\mathrm{CaO}(\%)$ & 0,50 & 0,32 \\
$\mathrm{Na}{ }_{2} \mathrm{O}(\%)$ & $-0,52$ & $-0,37$ \\
$\mathrm{~K}_{2} \mathrm{O}(\%)$ & $-0,83$ & 0,11 \\
$\mathrm{P}_{2} \mathrm{O}_{5}(\%)$ & 0,46 & 0,41 \\
$\mathrm{TiO} \mathrm{O}_{2}(\%)$ & 0,86 & 0,27 \\
$\mathrm{P} . \mathrm{F} .(\%)$ & 0,72 & 0,20 \\
$\mathrm{Cr}(\mathrm{mg} / \mathrm{Kg})$ & 0,88 & 0,56 \\
$\mathrm{Cu}(\mathrm{mg} / \mathrm{Kg})$ & 0,49 & 0,08 \\
$\mathrm{Ni}(\mathrm{mg} / \mathrm{Kg})$ & 0,10 & 0,41 \\
$\mathrm{~Pb}(\mathrm{mg} / \mathrm{Kg})$ & $-0,09$ & 0,38 \\
$\mathrm{Zn}(\mathrm{mg} / \mathrm{Kg})$ & 0,66 & 0,55 \\
$\mathrm{Zr}(\mathrm{mg} / \mathrm{Kg})$ & $-0,29$ & 0,08 \\
\hline
\end{tabular}

nificativa concentração de sulfato nas águas de chuva de São Paulo, cuja principal fonte é a oxidação do S(IV) emitido pela queima de combustíveis. O enxofre proveniente da combustão do petróleo possui intervalo de $\delta^{34} \mathrm{~S}$ típico que vai desde valores pouco menores que zero até $+10 \%$ (Clark e Fritz, 1997). Esses autores relataram os resultados obtidos por Niagru e Coker na bacia Great Lakes, Canadá, cuja variação de $\delta^{34} \mathrm{~S}$ ocorreu no intervalo entre 2 e $9 \%$, ressaltando-se os efeitos da sazonalidade e as características dos ambientes urbanos e rurais. Os valores mais baixos aparecem mais correlacionados ao enxofre biogênico, enquanto que os valores mais elevados refletem o enxofre dos combustíveis fósseis. Considerando os dados revelados pelos autores mencionados, os resultados obtidos no presente trabalho refletem os valores de $\delta^{34} S$ de fontes como fezes e detergentes existentes no esgoto doméstico e a precipitação atmosférica de enxofre proveniente da queima de combustíveis fósseis. Visto que esses valores obtidos se encontram em posição intermediária entre os valores determinativos dessas fontes. No entanto, o $\delta^{34} \mathrm{~S}$ obtido para amostra Jagua pode ser correlacionado com origem a partir de fertilizantes. 
No período de maior precipitação pluviométrica o enxofre presente no lodo de esgoto está mais correlacionado aos sulfatos insolúveis de chumbo e estrôncio, que correspondem às melhores correlações do enxofre com metais nesse período. Porém, o enxofre também se encontra como enxofre elementar, presente nos cristais formados sob as amostras do lodo quando micronizadas (Figura 2a). A oxidação de sulfeto a enxofre elementar também foi estudada em
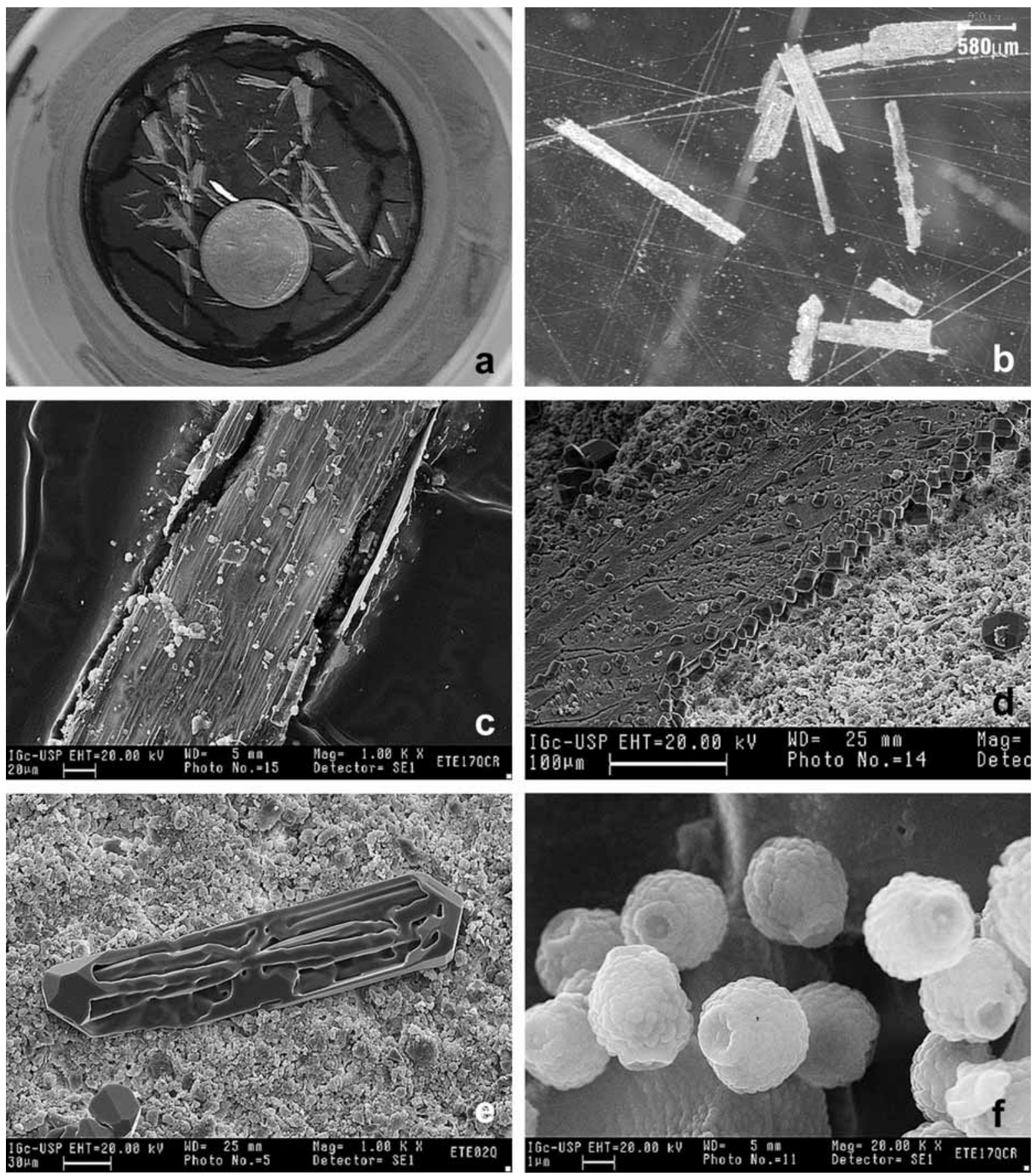

Figura 2. Imagem dos cristais de enxofre observados em microscópio eletrônico de varredura: a. sobre amostra de lodo de esgoto micronizadas; b. isolados da matriz lodo de esgoto e observados em microscópio óptico; c. cristal contendo enxofre; d. sobre matriz do lodo de esgoto apresentando zonas de dissolução com crescimento de minerais secundários nas bordas; e. nucleação não finalizada desses cristais; f. estruturas com provável origem biológica. 
efluentes por Molwantwa et al. (2004). A natureza dos cristais presentes nas amostras micronizadas de lodo, primeiramente estudada com o auxílio da difração de raios X (DRX) indica a presença de enxofre elementar (Figura 3). Esse resultado foi conflitante com a identificação visual desses cristais translúcidos, contrariamente a coloração amarela, típica desse elemento na natureza.

Os cristais isolados da matriz foram observados com auxílio de microscópio óptico (Figura 2b) e também ao MEV (Figura 2c). Com o mesmo recurso óptico, esses cristais contendo enxofre podem ser vistos sobre a matriz do lodo de esgoto (Figura 2d). Na estrutura cristalina foram observadas falhas na cristalização e zonas de dissolução com crescimento de minerais secundários nas bordas mais bem formados que os primários. Esses cristais apresentavam desenvolvimento interno da matriz cristalina, mas, com nucleação não finalizada, (Figura 2e). Em princípio é uma imagem que conduz a ser interpretada como processo de dissolução de cristais. No entanto, observação mais acurada demonstra que os pontos prováveis de dissolução encontram-se no centro das faces dos cristais e não nas arestas como seria de se esperar quando se trata de dissolução por erosão química. A explicação provável reside no processo de nucleação destes cristais com ausência de matéria prima, para completar a estrutura cristalina. Tal aspecto explicaria a existência de "vazios" residindo nas faces dos cristais incompletos. As análises por EDS realizadas em diversos cristais resultaram em composição química básica de enxofre (Figura 3). Uma possível explicação para o aparecimento desses cristais sobre as amostras micronizadas está no processo de cominuição em meio álcool etílico hidratado que pode ter concentrado compostos

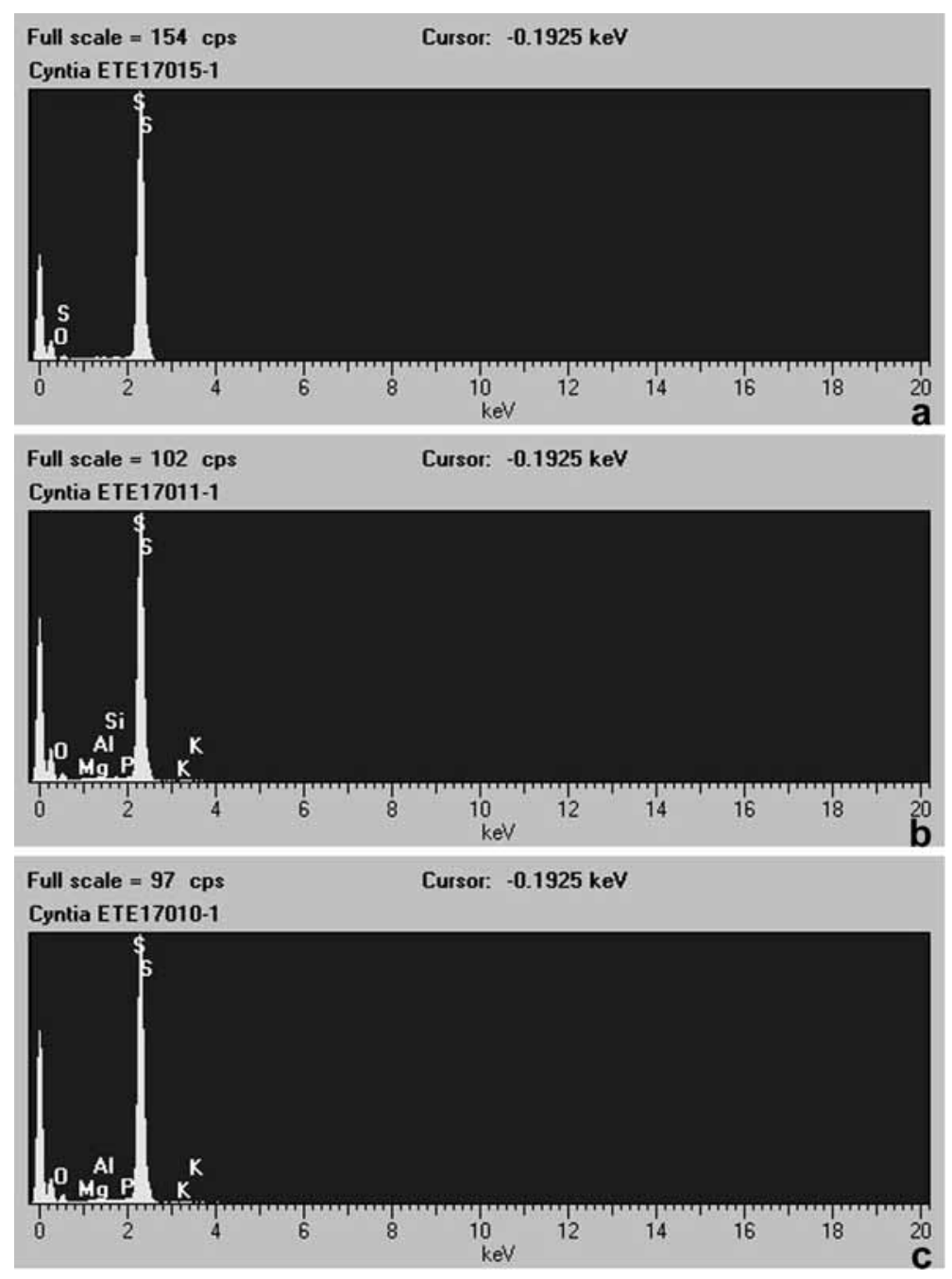

Figura 3. Espectros EDS relativos às análises pontuais: a. nos cristais; b e c. nas estruturas biológicas. 
de enxofre. Tais cristais devem ter origem fortemente associada à atividade biológica das sulfobactérias, existentes e desenvolvidas no lodo disposto.

Estruturas aparentemente de origem microbiológica também foram observadas com o recurso da microscopia eletrônica de varredura (Figura 2f). Espectros EDS (Figuras 3a, 3b e 3c) revelaram que o enxofre também se encontra na sua composição, ao menos na sua camada superficial, levando à hipótese de que esses organismos poderiam se tratar de bactérias redutoras de sulfato ou oxidantes de sulfetos, normalmente encontradas no lodo de esgoto durante o seu processo de tratamento anaeróbio na ETE. Porém, para que se pudesse realizar a caracterização desses organismos, seria necessário estudo complementar mais específico, com isolamento e identificação das espécies. Análise e investigação essa de difícil execução, bem como fora da proposta desse trabalho.

A compreensão do comportamento do enxofre presente nas amostras de lodo de esgoto é fundamental para o entendimento dos processos de tratamento de esgoto, principalmente no concernente à remoção de metais pesados que interferem nos processos biológicos de decomposição de matéria orgânica nos biodigestores. Sua origem e associações com outros elementos contribuem para a sua remoção por precipitação química, principalmente como sulfetos de metais pesados.

\section{CONCLUSÃO}

Os teores de enxofre presente nas amostras de lodo de esgoto da ETE Barueri apresentam concentrações e forma química que diferem pelo efeito da sazonalidade. A diluição ocasionada pela maior precipitação pluviométrica é indicada pelas menores concentrações de enxofre no período de maior precipitação pluviométrica, bem como pelas dos metais pesados Ni e Zn. Esse fato interfere nas associações mais evidentes entre o enxofre e outros elementos químicos no período de menor precipitação pluviométrica.

O enxofre presente no lodo de esgoto no período de menor precipitação pluviométrica encontra-se associado à matéria orgânica, compostos orgânicos sulfonados, como os surfactantes presentes nos detergentes e aos sulfatos de alumínio, ferro, cálcio, cromo, zinco e cobre.

No período de maior precipitação pluviométrica o enxofre presente no lodo de esgoto está mais correlacionado aos sulfatos insolúveis de chumbo e estrôncio, que correspondem às melhores correlações do enxofre com metais nesse período. A origem desse enxofre é atribuída aos compostos resultantes da decomposição das proteínas presentes nas fezes humanas, à presença de surfactantes e ao enxofre resultante da queima de combustíveis fósseis. Essa conclusão é indicada pelos valores obtidos de $\delta^{34} \mathrm{~S}$.
Por outro lado, fertilizantes e sulfato de alumínio utilizado no tratamento das águas de abastecimento como floculante contribuem para o estabelecimento dos valores intermediários obtidos nesse trabalho, o que sugere a indicação de mais de uma fonte para sua concentração observada nas amostras analisadas.

O ambiente altamente redutor do tratamento anaeróbio na ETE favorece a formação de enxofre elementar que foi extraído pelo álcool etílico utilizado no processo de micronização, cristalizando-se durante a secagem da amostra em estufa. Os espectros obtidos por DRX e MEV/EDS comprovaram a composição desses cristais.

\section{AGRADECIMENTOS}

Ao CNPq pela bolsa de formação de pesquisador de doutorado, processo 140998/2004-7. À SABESP pela permissão para a coleta das amostras de lodo de esgoto da ETE Barueri. Ao Laboratório de Microscopia de Varredura do IGc/USP pela colaboração na obtenção das imagens e análises por EDS e ao Centro de Estatística Aplicada (CEA), do Instituto de Matemática e Estatística da USP, pela colaboração nas análises estatísticas dos dados.

\section{REFERÊNCIAS}

ANDREWS, J. E.; BRIMBLECOMBE, P.; JICKELLS, T. D.; LISS, P. S. Glogal change. In: ANDREWS, J. E.; BRIMBLECOMBE, P.; JICKELLS, T. D.; LISS, P. S. An introduction to environmental chemistry. Oxford: Blackwell Science Ltd., 1996. p. 182-193.

BETTIOL, W.; CAMARGO, O. A. Lodo de esgoto na agricultura: potencial de uso e problemas. Tec hoje (Boletim Técnico), 2004.

BUSSAB, W. O.; MORETTIN, P. A. Estatística básica. 5. ed. São Paulo: Saraiva, 2006. 520 p.

CHAGAS, W. F. Estudo de patógenos e metais em lodo digerido bruto e higienizado para fins agrícolas, das estações de tratamento de esgotos da Ilha do Governador e da Penha no Estado do Rio de Janeiro. 2000. 89 p. Dissertação (Mestrado) - Fundação Oswaldo Cruz, Escola Nacional de Saúde Pública, Rio de Janeiro, 2000.

CHARLSON, R. J.; WIGLEY, T. M. L. Sulfate aerosol and climatic change. Scientific American, New York, v. 270, n. 2, p. 28-35, 1994.

CLARK, I. D.; FRITZ, P. Environmental isotopes in hydrogeology. New York: Lewis Publishers, 1997. 144 p. 
CONOVER, W. J. Practical nonparametric statistics. 3. ed. Texas Tech University: John Wiley \& Sons, 2001. 584 p.

CRAVOTTA, C. A. Use of stable isotopes of carbon, nitrogen, and sulfur to identify sources of nitrogen in surface waters in the lower Susquehanna River Basin, Pennsylvania. Denver, CO: U.S. Geological Survey, 1997. 90 p. (U.S. Geological Survey water-supply paper 2497).

FORESTI, E.; FLORÊNCIO, L.; HAANDEL, A. V.; ZAIAT, M.; CAVALCANTI, P. F. F. Fundamentos do tratamento anaeróbio. In: CAMPOS, J. R. (Coord.). Tratamento de esgotos sanitários por processo anaeróbio $e$ disposição controlada no solo. Rio de Janeiro: ABES, 1999. p. 29-50.

JANASI, V. A.; ANDRADE, S.; ULBRICH, H. H. G. J. A correção do drift instrumental em ICO-AES com espectrômetro seqüencial e a análise de elementos maiores, menores e traços em rochas. Boletim IG-USP, Série Científica, São Paulo, v. 26, p. 45-58, 1996.

JORDÃO, E. P.; PESSÔA, C. A. Tratamento de esgotos domésticos. 3. ed. Rio de Janeiro: ABES. 720 p., 1995

KROUSE, H. R.; GRINENKO, V. A. Stable Isotopes: Natural and Antropogenic Sulphur in the Environment. SCOPE 43. Scientific Committee on Problems of the Environment (SCOPE) of the International Council of Scientific Unions (ICSU) in collaboration with United Nations Environment Programme. John Wiley \& Sons. p. 1991. 464 p.

LAWRENCE, A. W.; McCARTY, P. L. The role of sulfide in preventing heavy metal toxicity in anaerobic treatment. Journal Water Pollution. Control Federation, New York, v. 37, p. 392-406. 1965.

LEAL, T. F. M.; FONTENELE, A. P. G.; PEDROTTI, J. J.; FORNARO, A. Composição iônica majoritária de águas de chuva no centro da cidade de São Paulo. Química Nova, São Paulo, v. 27, n. 6, p. 855-861, 2004.

MASSELLI, J. W.; MASSELLI, N. W.; BURFORD, M. G. Sulfide saturation for better digester performance. Journal Water Pollution Control Federation, New York, v. 39, p. 1369-1373. 1967.

MOLWANTWA, J. B.; COETSER, S. E.; HEALTH, R.; ROSE, P. D. Development of the floating sulphur biofilm reactor for sulphide oxidation in biological water treatment systems. Water SA, Pretoria, v. 30, n. 5, Special Edition, p. 655-657, 2004.
MORAES, M. P. G. Determinação de metais pesados em lodo de esgoto por espectrometria de fluorescência de raios X. 2003. 54 p. Dissertação (Mestrado) - Instituto de Geociências, Universidade Estadual de Campinas, Campinas, 2003.

MORPER, M.; FURST, P. Biological removal of heavy metals from printed circuit board and electroplating wastewaters in Metex process systems. Linde Reports on Science and Technology, Austrália, n. 49, p. 40-42. 1991.

RIZZO, A. C. de L.; LEITE, S. G. F. Produção de sulfeto em reator do tipo UASB e sua potencial aplicação na remoção de metia pesados e efluentes. Rio de Janeiro: CETEM/MCT, 2004. 108 p.

ROS, A.; MONTES-MORAN, M. A.; FUENTE, E.; NEVSKAIA, D. M.; MARTIN, M. J. Dried sludges and sludge-based chars for $\mathrm{H}_{2} \mathrm{~S}$ removal at low temperature: influence of sewage sludge characteristics. Environ. (supporting information), Science Technology, v. 40, p. 302-309, 2006.

STUMM, W.; MORGAN, J. J. Aquatic chemistry: chemical equilibrium and rates in natural waters. Wiley, N. Y. 1995. 1040 p.

TEIXEIRA, L. B.; OLIVEIRA, R. F.; FURLAN JUNIOR, J.; CHENG, S. S. Comparação de composto orgânico de Barcarena com adubos orgânicos tradicionais quanto às propriedades químicas. Comunicado Técnico, Belém, PA, n. 70, 2002.

TSUTIYA, M. T. Características de biossólidos gerados em estações de tratamento de esgotos. In: TSUTIYA, M.T.; COMPARINI, J. B.; SOBRINHO, P. A.; HESPANHOL, I.; CARVALHO, P. C. T.; MELFI, A. J.; MELO, W. J.; MARQUES, M. O. (Eds.). Biossólidos na agricultura. 2. ed. São Paulo: ABES/SP, 2002. p. 89-131.

WEST, H. M.; CAWLEY, J.; WILLS, R. Analysis and characterization of water treatment plant sludges by X-ray fluorescence spectrometry. The Analyst, London, v. 120, p. 1267-1271, 1995. 